\title{
Comparison of External and Internal Fixation for Management of Bicondylar Tibial Plateau Fractures in Terms of Surgical Site Infection
}

\author{
Muhammad Javaid lqbal, Afzal Javid, Shahzad Mahmood Shahid, Fida Hussain, Allah Rakha
}

\begin{abstract}
Objective: To compare external and internal fixation for the management of bicondylar tibial plateau fractures in terms of surgical site infection (SSI). Study Design: Randomized Controlled Trial. Settings: Faisalabad Medical University and affiliated Hospitals, Faisalabad, Pakistan. Duration: May 15, 2017 to November 15, 2017. Methodology: Approval from the institutional ethical committee was taken. All the patients with diagnosis of Bicondylar (Schatzker types $\mathrm{V}$ and $\mathrm{VI}$ ) tibial plateau fractures in acute trauma setting who fulfilled the selection criteria were entered in the study by taking informed written consent. All selected cases were guided/informed regarding risk and benefits of the procedure. Randomization was based on computer generated numbers and allotted A \& B groups. Group A patients underwent open reduction and internal fixation and in Group B patients' external fixation with illizarove ring fixator was applied. All the relevant information was filled on predesigned Performa. Post-operative superficial surgical site infection was noted at 4 weeks after surgery in the ward of each patient. According to the Centre of Disease Control and prevention (CDC) and Healthcare Infection Control Practices Advisory Committee (HICPAC) criteria for defining a superficial surgical site infection, the record from each patient was collected after carefully examining the surgical wound at 4 weeks after surgery. Results: Post-operative superficial surgical site infection was $10 \%(n=4)$ in cases of Group-A and 47.5\%(n=19) in cases of Group-B, whereas 90\%(n=36) in Group-A and 52.5\%(n=21) in Group-B had no SSI. Conclusion: We found lower rate of infection in cases treated with internal fixation than those undergoing external fixation for bicondylar tibial plateau fractures.
\end{abstract}

Keywords: Tibial plateau fractures, Bicondylar (type V \& VI), External fixation, Internal fixation, Surgical site infection.

Corresponding Author

Submitted for Publication: 12-11-2019

Accepted for Publication: 21-01-2020

DR. AFZAL JAVID, Senior Registrar of Orthopedics, DHQ Hospital, Faisalabad-Pakistan.

Contact / Email: +92 333-6866703,dr_afzaal703@yahoo.com

Citation: Iqbal MJ, Javid A, Shahid SM, Hussain F, Rakha A. Comparison of External and Internal Fixation for Management of Bicondylar Tibial

Plateau Fractures. APMC 2020;14(1):24-7.

\section{INTRODUCTION}

Proximal tibia fractures with intra-articular extensions are found in only $1.2 \%$ of all fractures. It is commonly found in younger age group due to high-energy trauma, whereas older age group due to fragility. ${ }^{1}$ The commonest cause of these fractures (Schatzker types $\mathrm{V}$ and $\mathrm{VI}$ ) is high-energy trauma. The aim of the treatment is to achieve mobile, stable, pain-free and wellaligned joint by reducing the risk of post-traumatic osteoarthritis. $^{2}$

The commonly used technique to fix this fracture is open reduction and internal fixation (ORIF) by using plate and screws. In our practice extended anterior incision is used for prevention of soft tissue envelope. ${ }^{3}$ The commonest cause of this fracture is high energy accidents; however, ORIF in these circumstances associated with soft tissue damage and wound complications including infection and skin necrosis. ${ }^{4}$ Soft tissue complications delay in operative fixation/ORIF is contraindicated usually. Due to the above-mentioned complications, alternative procedures like minimally invasive plate osteosynthesis (MIPO), and hybrid external fixation were invented. ${ }^{5,6}$

The hybrid external fixation technique is a different modality. Fracture is reduced by using closed manipulation, percutaneous screws, or through small incisions and an application of external fixator (ilizarove -circular frame usually).

ORIF is considered a successful procedure for restoration of articular congruity; however, it compromises the soft tissue cover usually. Several trials reveal that ORIF of these fractures is followed by the risk of development of deep wound infection and wound breakdown. ${ }^{7}$ Such grave complications can be decreased by using an external fixator. The ilizarove technique is found with good clinical outcome and good alternative treatment option for fixation of proximal tibial fractures. ${ }^{6}$ Those studies reported high rates of unplanned secondary procedures which included incision and drainage, soft tissue flaps, redo ORIF, plate removal, knee manipulation, total knee replacement and even above knee amputation.

The superficial surgical site infection rate in internal fixation it is $7.4 \%,{ }^{8}$ whereas in external fixation of tibial plateau fractures is $42.8 \%{ }^{9}$

The rationale of my study is based on hypothesis that the external fixator preserves soft tissue envelope and with it we can achieve lower rate of superficial surgical site infection. ${ }^{7}$ So, a good prospective study involving large number of patients is required to establish a protocol to minimize post-operative complications for this type of injuries.

\section{METHODOLOGY}

Study Design: Randomized Controlled Trial.

Settings: Faisalabad Medical University and affiliated Hospitals, Faisalabad, Pakistan.

Duration: May 15, 2017 to November 15, 2017.

Sample Size: A total of 80 cases in two equal groups.

Sample Technique: Non-probability consecutive sampling. 
Inclusion Criteria: Patients with the diagnosis of Bicondylar (Schatzker types $\mathrm{V}$ and $\mathrm{VI}$ ) tibial plateau fractures in acute trauma setting in patients between 18-65 years of age with Bicondylar (OTA C1, C2, and C3) tibial plateau fractures of either gender with Close fractures and open type 1 Gustilo Anderson were the part of our study.

Exclusion Criteria: We excluded all cases with pathological bicondylar tibial plateau fracture with or without trivial injury, having fractures schatzker Types I, II, III and IV and having absolute (medically unfit, associated with other injuries) and relative (Quack treated old fractures).

Methods: All the patients fulfilling the inclusion criteria were entered in the study after informed written consent. All selected patients were guided/informed regarding benefits and risk of the procedure. Randomization was based on computer-generated numbers and allotted $A$ or $B$ groups. Group $A$ patient underwent open reduction and internal fixation through medial approach and Group $B$ patient underwent external fixation (ilizarov ring fixator). All the relevant information was filled on predesigned Performa (Annexure 1). Post-operative superficial surgical site infection was noted at 4 weeks after surgery in the ward of each patient. According to the Centre of Disease Control and prevention (CDC) and Healthcare Infection Control Practices Advisory Committee (HICPAC) criteria for defining a superficial surgical site infection, the record from each patient was collected after carefully examining the surgical wound at 4 weeks after surgery. We analyze the data for comparison in both groups with the help of SPSS-20.

\section{RESULTS}

Patients were distributed in age groups which shows that $57.5 \%$ $(n=23)$ in cases of Group-A and $65 \%(n=26)$ in cases of $B$ Group were between $18-40$ years of age whereas $42.5 \%(n=17)$ in Group-A and 35\% ( $n=14)$ in Group-B were between 41-65 years. Mean $\pm S D$ was calculated as $40.78 \pm 7.74$ years in cases of Group-A and 39.3+8.35 years in cases of Group-B. (Table No. 1)

Table 1: Age distribution $(n=80)$

\begin{tabular}{|c|c|c|c|c|}
\hline \multirow{2}{*}{ Age (in years) } & \multicolumn{2}{|c|}{ Group-A ( $=40)$} & \multicolumn{2}{c|}{ Group-B ( $=40)$} \\
\cline { 2 - 5 } & Cases & $\%$ & Cases & $\%$ \\
\hline $18-40$ & 23 & 57.5 & 26 & 65 \\
\hline $41-65$ & 17 & 42.5 & 14 & 35 \\
\hline Total & 40 & 100 & 40 & 100 \\
\hline Mean +SD & \multicolumn{2}{|c|}{$40.78 \pm 7.74$} & \multicolumn{2}{|c|}{$39.3 \pm 8.35$} \\
\hline
\end{tabular}

Patients were distributed according to gender showing that $70 \%$ $(n=28)$ in cases of Group-A and $75 \%(n=30)$ in cases of GroupB were male while remaining $30 \%(n=12)$ in cases of Group-A and $25 \%(n=10)$ in cases of Group-B were females. (Table 2)
Table 2: Gender distribution $(n=80)$

\begin{tabular}{|c|c|c|c|c|}
\hline \multirow{2}{*}{ Gender } & \multicolumn{2}{|c|}{ Group-A (n=40) } & \multicolumn{2}{c|}{ Group-B (n=40) } \\
\cline { 2 - 5 } & Cases & $\%$ & Cases & $\%$ \\
\hline Male & 28 & 70 & 30 & 75 \\
\hline Female & 12 & 30 & 10 & 25 \\
\hline Total & 40 & 100 & 40 & 100 \\
\hline
\end{tabular}

Patients were distributed according to BMl of the patients which shows that $62.5 \%(n=25)$ in cases of Group-A and $67.5 \%(n=27)$ in cases of Group-B had $<30$ while remaining $37.5 \%(n=15)$ in Group-A and $32.5 \%(n=13)$ in Group-B had $\geq 30$ BMl. Type of fracture shows that $52.5 \%(n=21)$ in Group-A and $45 \%(n=18)$ in Group-B had type $V$ fracture while remaining $47.5 \%(n=19)$ in Group-A and 55\%(n=22) in Group-B had type VI fracture.

Comparison of post-operative superficial surgical site infection in these fractures treated by external fixation and internal fixation shows that $10 \%(n=4)$ in Group-A and $47.5 \%(n=19)$ in Group-B had surgical site infection whereas $90 \%(n=36)$ in Group-A and $52.5 \%(n=21)$ in Group-B had no SSU, p value was 0.0002. (Table No. 3)

Table 3: Comparison of post-operative superficial surgical site infection of operatively treated bicondylar tibial plateau fractures by external fixation and internal fixation $(n=80)$

\begin{tabular}{|c|c|c|c|c|}
\hline \multirow{2}{*}{ SSI } & \multicolumn{2}{|c|}{ Group-A (n=40) } & \multicolumn{2}{c|}{ Group-B ( $\mathrm{n}=40)$} \\
\cline { 2 - 5 } & No. of patients & $\%$ & No. of patients & $\%$ \\
\hline Yes & 4 & 10 & 19 & 47.5 \\
\hline No & 36 & 90 & 21 & 52.5 \\
\hline Total & 40 & 100 & 40 & 100 \\
\hline
\end{tabular}

$P$ value $=0.0002$

\section{DISCUSSION}

In our study, mean age was calculated as $40.78+7.74$ years in Group-A and $39.3+8.35$ years in Group-B, $70 \%(n=28)$ in Group$A$ and $75 \%(n=30)$ in Group-B were male while remaining $30 \%(n=12)$ in Group-A and $25 \%(n=10)$ in Group-B were females, comparison of post-operative superficial surgical site infection was 10\%(n=4) in Group-A and $47.5 \%(n=19)$ in Group$B$, whereas $90 \%(n=36)$ in Group-A and $52.5 \%(n=21)$ in Group$B$ had no SSI, $p$ value was 0.0002 .

Our data for superficial surgical site infection is comparable with the previous literature that is $42.8 \%$ in external fixation and $7.4 \%$ in internal fixation. 8,9

CC Chan and others ${ }^{10}$ compared the outcome of external fixation and internal fixation in terms of Rasmussen score, need of total knee replacement (TKR) and development of osteoarthritis. Infection was recorded significantly higher in cases treated with external fixation (9 patients, $26 \%$ ) because www.apmcfmu.com 
of pin tract infection, whereas in patients treated by internal fixation no deep infections was reported.

External fixation treatment is surgically less invasive and soft tissue complications are minimal. In our study, pin tract infections were the well-recognized complication which is common with illizarove external fixation.

In a study by Mallik et al (1992) which included 10 patients, three of them were treated with external fixator whereas the remainders seven were treated with internal fixation. ${ }^{11}$ Although they reported high rate of infection in internal fixation group but due to small data size any firm conclusion about treatment options cannot be withdrawn.

A second posteromedial incision with limited surgical exposure limits the complication rate of wound infection. ${ }^{12}$ This posteromedial incision is a good option in selected cases where a large posteromedial fragment is a part of bicondylar tibial plateau fracture. ${ }^{13}$

The findings of our results are primary in this regard and needs to be validated through some other trials (multicenter), which will further helpful while deciding to choose the method of fixation of bicondylar tibial plateau fracture.

\section{CONCLUSION}

Based on our results, internal fixation was found to be less infected as compared to external fixation for bicondylar tibial plateau fractures.

\section{LIMITATIONS}

The sample size of our study (40 cases in each group) is small, moreover, the study is conducted in a single center (Faisalabad Medical University and affiliated hospitals whose results cannot be generalized.

\section{SUGGESTIONS / RECOMMENDATIONS}

The findings of our results need to be validated through some other trials (multicenter), which will further helpful while deciding to choose the method of fixation of bicondylar tibial plateau fracture.

\section{CONFLICT OF INTEREST / DISCLOSURE}

No conflict of interest to be declared.

\section{ACKNOWLEDGEMENTS}

We acknowledge our residents especially Dr. M. Umar, Dr. Usman siddique and Dr. Usman Akmal who helped us in collecting the data and counseling of the patients.

\section{REFERENCES}

1. Biggi F, Di Fabio S, D'Antimo C, Trevisani S. Tibial plateau fractures: internal fixation with locking plates and the MIPO technique. Injury. 2010;41(11):1178-82.

2. Jansen H, Frey SP, Doht S, Fehske K, Meffert RH. Medium-term results after complex intra-articular fractures of the tibial plateau. J Orthop Sci. 2013;18(4):569-77.

3. Metcalfe D, Hickson CJ, McKee L, Griffin XL. External versus internal fixation for bicondylar tibial plateau fractures: systematic review and meta-analysis. J Orthop Traumatol. 2015;16(40):27585.

4. Ramos T, Ekholm C, Eriksson Bl, Karlsson J, Nistor L. The llizarov external fixator - a useful alternative for the treatment of proximal tibial fractures: a prospective observational study of 30 consecutive patients. BMC Musculoskelet Disord. 2013;14:11.

5. Ariffin HM, Mahdi NM, Rhani SA, Baharudin A, Shukur MH. Modified hybrid fixator for high-energy Schatzker $\mathrm{V}$ and VI tibial plateau fractures. Strategies Trauma Limb Reconstr. 2011;6(1):21-6.

6. Ali AM. Outcomes of open bicondylar tibial plateau fractures treated with llizarov external fixator with or without minimal internal fixation. Eur J Orthop Surg Traumatol. 2013;23(3):34955.

7. Pun TB, Krishnamoorthy VP, Poonnoose PM, Oommen AT, Korula RJ. Outcome of Schatzker type V and VI tibial plateau fractures. Indian J Orthop. 2014:48(1):35-41.

8. Lin S, Mauffrey C, Hammerberg EM, Stahel PF, Hak DJ. Surgical site infection after open reduction and internal fixation of tibial plateau fractures. Eur J Orthop Surg Traumatol. 2014;24(7):797803.

9. El-Alfy B, Othman A, Mansour E. Indirect reduction and hybrid external fixation in management of comminuted tibial plateau fractures. Acta Orthop Belg. 2011;77(3):349-54.

10. CC Chan, J Keating. Comparison of Outcomes of Operatively Treated Bicondylar Tibial Plateau Fractures by External Fixation and Internal Fixation. Malays Orthop J. 2012;6(1):7-12.

11. Mallik AR, Covall DJ, Whitelaw GP. Internal versus external fixation of bicondylar tibial plateau fractures. Orthop Rev. 1992;21(12):1433-16.

12. Barei DP, Nork SE, Mills WJ, Henley MB, Benirschke SK. Complications associated with internal fixation of high-energy bicondylar tibial plateau fractures utilizing a two-incision technique. J Orthop Trauma. 2004;18(10):649-57.

13. Carlson DA. Posterior bicondylar tibial plateau fractures. J Orthop Trauma. 2005;199(2):73-8. 


\section{AUTHORSHIP AND CONTRIBUTION DECLARATION}

\begin{tabular}{lc} 
AUTHORS & Contribution to The Paper \\
\hline $\begin{array}{l}\text { Dr. Muhammad Javaid Iqbal } \\
\text { Professor \& Head of Orthopedics } \\
\text { FMU / DHQ Hospital, Faisalabad Pakistan }\end{array}$ & Proof Reading, Results Interpretation \\
\hline $\begin{array}{l}\text { Dr. Afzal Javid } \\
\text { Senior Registrar, Orthopedics } \\
\text { DHQ Hospital, Faisalabad Pakistan }\end{array}$ & Principal Investigator, Data Collection \\
\hline $\begin{array}{l}\text { Dr. Shahzad Mahmood Shahid } \\
\text { Senior Registrar, Orthopedics } \\
\text { DHQ Hospital, Faisalabad Pakistan }\end{array}$ & Analytic Work \\
\hline $\begin{array}{l}\text { Dr. Fida Hussain } \\
\text { Medical Officer, Orthopedics } \\
\text { Govt. General Hospital, Samanabad Faisalabad Pakistan }\end{array}$ & Data Collection, Discussion Writing \\
\hline $\begin{array}{l}\text { Dr. Allah Rakha } \\
\text { Senior Registrar, Orthopedics }\end{array}$ & Proof Reading \\
DHQ Hospital, Faisalabad Pakistan &
\end{tabular}

